\title{
Second-generation EGFR and ErbB tyrosine kinase inhibitors as first-line treatments for non-small cell lung cancer
}

This article was published in the following Dove Press journal: OncoTargets and Therapy

\author{
Shouzheng Wang \\ Junling $\mathrm{Li}$
}

Department of Medical Oncology, National Cancer Center/National Clinical Research Center for Cancer/Cancer Hospital, Chinese Academy of Medical Sciences and Peking Union Medical College, Beijing, People's Republic of China
Correspondence: Junling $\mathrm{Li}$ Department of Medical Oncology, National Cancer Center/National Clinical Research Center for Cancer/Cancer Hospital, Chinese Academy of Medical Sciences and Peking Union Medical College, Beijing I0002I, People's Republic of China

Tel +86I 380 II $7889 \mid$

Fax +861080115555566181

Email lijunling@cicams.ac.cn

\begin{abstract}
The discovery that mutations in the EGFR gene are present in up to $50 \%$ of patients with lung adenocarcinoma, and the development of highly efficacious EGFR tyrosine kinase inhibitors (TKIs), has revolutionized the way this common malignancy is treated. Three generations of EGFR TKIs are now approved for use in EGFR mutation-positive non-small cell lung cancer (NSCLC); the first-generation agents erlotinib, gefitinib, and icotinib; the second-generation ErbB family blockers afatinib and dacomitinib; and most recently, osimertinib, a third-generation EGFR TKI. The second-generation agents have demonstrated impressive efficacy relative to both standard platinum-based chemotherapy and first-generation EGFR TKIs, significantly improving response and progression-free and overall survival. Data from real-world studies suggest that afatinib is as effective and well tolerated in routine clinical practice as it is in clinical studies and is effective in patients with certain uncommon EGFR mutations, patients with brain metastases, and older patients. Few real-world data are available for dacomitinib in the first-line setting. Afatinib and dacomitinib have similar safety profiles, with acne/skin dryzness, diarrhea, stomatitis, and paronychia the most common adverse events (AEs) reported in clinical and real-world studies. Numerous studies have shown that tolerability-guided dose reductions can help manage afatinibrelated AEs without reducing efficacy. As the number of therapeutic options for advanced NSCLC increases, the optimal choice for first-line treatment will be determined by considering patient factors such as the presence of brain metastases, the type of EGFR mutation, tolerability, and subsequent therapy options for long-term treatment.
\end{abstract}

Keywords: afatinib, dacomitinib, epidermal growth factor receptor, non-small-cell lung cancer

\section{Plain language summary}

The EGFR plays an important role in cell signaling, but when incorrectly formed, may stimulate the uncontrolled growth of normal cells. The discovery that mutations in the epidermal growth factor receptor $(E G F R)$ gene are present in up to $50 \%$ of patients with lung adenocarcinoma, and the development of highly effective treatments targeting tumor cells with these mutations, has revolutionized the way non-small-cell lung cancer is treated. In this article, we describe the development and clinical use of the second-generation EGFR tyrosine kinase inhibitors (TKIs), afatinib and dacomitinib. Many patients do not respond to firstgeneration EGFR TKIs, or subsequently become resistant to the anti-cancer effects of EGFR TKIs. The second-generation EGFR TKIs were developed to try and address these problems. Results from clinical studies have shown that afatinib and dacomitinib improve response and survival compared with chemotherapy and first-generation EGFR TKIs. The drugs are generally well tolerated, but in patients experiencing unbearable side effects, the dose of afatinib can be reduced without reducing its effectiveness. Data from patients receiving afatinib in 
routine clinical practice have demonstrated that it is as effective and well tolerated in the real-world setting as it is in clinical studies. Further, it has demonstrated efficacy in patients with brain metastases, in older individuals, and in patients with certain uncommon EGFR mutations.

\section{Introduction}

Despite advances in treatment, lung cancer continues to be the world's most lethal malignancy, taking the lives of an estimated 1.76 million individuals in 2018, more than double the amount claimed by the next biggest killer, colorectal cancer. ${ }^{1}$ Around $85-90 \%$ of lung cancer is non-small-cell lung cancer (NSCLC) and within NSCLC, adenocarcinoma and squamous cell carcinoma are the most frequently encountered subtypes. ${ }^{2}$ In recent years, a number of molecular alterations involved in the development of NSCLC have been identified, including rearrangements in the $A L K$ gene $^{3}$ and mutations or deletions in the EGFR gene. ${ }^{4,5} E G F R$ encodes the EGFR (also known as ErbB1), a member of the ErbB family of receptor tyrosine kinases (RTKs). Other family members include HER2 (neu, ErbB2), HER3 (ErbB3), and HER4 (ErbB4). ${ }^{6}$ The ErbB RTKs are involved in intracellular signaling cascades that promote cell proliferation and survival, but can also drive malignant transformation. ${ }^{7,8}$

Mutations in the EGFR gene are observed frequently in patients with lung adenocarcinoma, ${ }^{9}$ but are rare in squamous cell carcinoma. ${ }^{10}$ Approximately $50 \%$ of Asian adenocarcinoma patients carry EGFR mutations, ${ }^{11,12}$ including $49 \%$ of Chinese patients, ${ }^{13}$ compared with $14-17 \%$ of Caucasian adenocarcinoma patients. ${ }^{5,9,14}$ The most common EGFR mutations, also known as the classical mutations, are inframe deletions in exon 19 (del19; 49-72\% of EGFR mutations) and a nucleotide substitution within codon 858 of exon 21 (L858R; 28-43\%). ${ }^{4,14-21}$ Other EGFR mutations have been detected in 7-23\% of patients and include the G719X ( $\sim 30 \%$ of uncommon mutations), L861Q (13-35\%), and S768I ( 5\%) mutations. ${ }^{11,14,17,18,22-25}$

In recent years, numerous therapies targeting the EGFR have been developed and subsequently integrated into routine clinical use. The EGFR tyrosine kinase inhibitors (TKIs) are small molecules that bind to, and interfere with, the catalytic activity of EGFR. ${ }^{26}$ Three firstgeneration EGFR TKIs are currently in routine clinical use: erlotinib, gefitinib, and icotinib. In the United States, erlotinib is approved for the first or subsequent line treatment of EGFR mutation-positive (exon 19 deletions or L858R mutations) patients with metastatic NSCLC; ${ }^{27}$ similar approvals are in place in Europe and elsewhere. ${ }^{28}$ In contrast, gefitinib is indicated in both the United States and Europe as first-line therapy only. ${ }^{29,30}$ Icotinib is only available in China and is approved for the treatment of EGFR mutation-positive NSCLC patients in any treatment line. ${ }^{31}$

In the first-line setting, erlotinib, gefitinib, and icotinib are associated with median progression-free survival (PFS) of 5.7-13.1 months, compared with 4.6-7.9 months with platinum-based chemotherapy. ${ }^{16,32-37}$ However, in the first-line setting, none of the first-generation EGFR TKIs has demonstrated an overall survival (OS) benefit vs chemotherapy, and almost all patients develop resistance to first-generation agents. Although numerous resistance mechanisms have been identified, the most common is an acquired missense mutation in exon 20 of EGFR (T790M), which has been detected in over half of patients with acquired resistance. ${ }^{38-40}$ Other resistance mechanisms include amplification of the MET receptor tyrosine kinase, acquired PIK3CA mutations, or EGFR amplifications. $^{40-42}$ A number of EGFR mutation-positive patients are resistant to first-line EGFR TKI treatment; this may be due to additional mutations in $E r b B 2$ or mutations elsewhere in EGFR, such as exon $20 .^{43,44}$ Clearly, agents with inhibitory profiles extending beyond the common activating mutations were needed, and this provided the rationale for the development of the second-generation EGFR TKIs.

\section{Literature search strategy}

We searched the published literature (English language only) for articles and presentations that reported clinical efficacy and safety of the second-generation EGFR TKIs afatinib and dacomitinib. Relevant publications were identified by means of searches of U.S. National Library of Medicine (NLM) PubMed, using the search terms [efficacy] OR [safety] AND [Drug name (for each EGFR TKI)]. Reports of clinical trials and real-world evidence were included. Other relevant publications were identified from citations in the key publications identified via NLM PubMed and searches of abstracts published at recent major oncology meetings over the past 3 years, including annual meetings of the American Society of Clinical Oncology, European Society of Medical Oncology, European Lung Cancer Congress, and the World Conference on Lung Cancer. Further information was obtained from the US and EU prescribing information for each agent.

\section{Clinical development of second-generation ErbB family TKIs} The second-generation ErbB family TKIs afatinib and dacomitinib were developed to address the issue of 
acquired resistance in patients with EGFR mutationpositive NSCLC and extend the inhibitory profile to $E G F R$ mutations that were resistant to the firstgeneration TKIs. Afatinib is an ATP-competitive anilinoquinazoline derivative (Figure 1A) that binds to its targets by forming a covalent adduct with the active site sulfhydryl group of a cysteine residue through Michael addition reaction, thereby irreversibly blocking the kinase activity of all ErbB family members. ${ }^{26}$ Importantly, formation of this covalent adduct seems central to the activity of afatinib across all ErbB family members. Like afatinib, dacomitinib is an irreversible pan-ErbB inhibitor (Figure 1B), which also covalently binds to key residues within EGFR and inhibits kinase activity. ${ }^{45}$ These agents have a broader inhibitory profile than the first-generation TKIs; this more complete blockade of the ErbB family was expected to enhance the effect on important signaling pathways. Initial in vitro studies demonstrated that afatinib potently suppressed the kinase activity of wild-type and activated EGFR and ErbB2 mutants, including erlotinib-resistant isoforms ${ }^{46}$ Further, afatinib inhibited the survival of lung cancer cell lines harboring wild-type or L858R/T790Mmutant EGFR, or mutated ErbB2, and induced tumor regression in xenograft models expressing the double mutation L858R/T790M or mutated ErbB2. ${ }^{46-48}$ Similarly, dacomitinib was shown to be a potent inhibitor of cells harboring EGFR-activating mutations as well as T790M resistance mutations ${ }^{45}$ and caused marked regressions in a variety of human tumor xenograft models that expressed and/or over-expressed ErbB family members or contained L858R/T790M-mutant EGFR. ${ }^{49}$ Additionally, dacomitinib is a highly effective inhibitor of wild-type

A

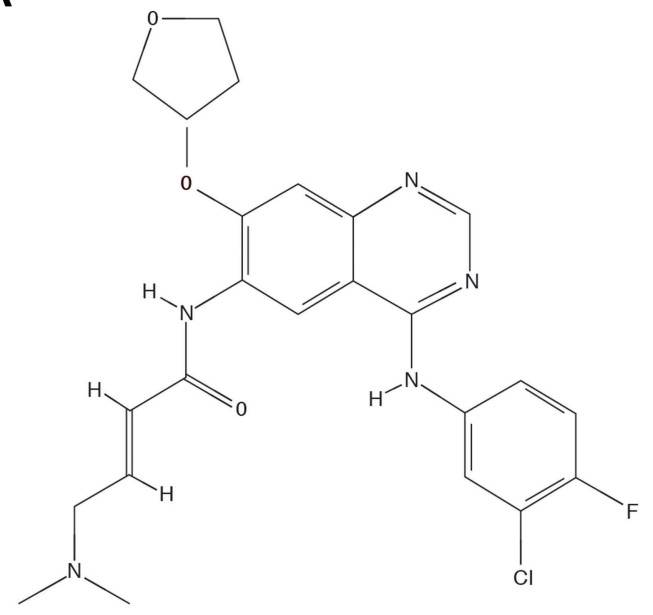

ErbB2 ${ }^{45}$ Notably, preclinical data showed afatinib and dacomitinib to be more potent than first-generation TKIs against wild-type cells, those harboring the common activating mutations, and those with less common mutations, including T790M. ${ }^{45-47,49}$

\section{Clinical efficacy in EGFR mutation-positive advanced NSCLC patients treated in the first-line setting} Afatinib

The global, Phase III LUX-Lung 3 study randomized 345 patients with EGFR mutation-positive NSCLC (del19, L858R, or uncommon mutations) to first-line treatment with afatinib or cisplatin and pemetrexed. ${ }^{20}$ Patients receiving afatinib had significantly longer PFS (HR $=0.58, p=0.001)$ and significantly higher objective response rates (ORR) than those receiving cisplatinpemetrexed (Table 1), although median OS was similar between the two arms (31.6 vs 28.2 months, $P=0.11$ ) (Figure 2A). ${ }^{50}$ Similarly, the Phase III LUX-Lung 6 study randomized 364 Asian patients with EGFR mutation-positive NSCLC (del19, L858R, or uncommon mutations) to afatinib or cisplatin and gemcitabine. ${ }^{21}$ Like LUX-Lung 3, ORR and PFS were both significantly improved with afatinib vs cisplatin-gemcitabine. ${ }^{21}$ However, despite the observed PFS and ORR benefits, no differences in OS were seen (Figure 2B) ${ }^{50}$ In the Phase IIb LUX-Lung 7 study ( $\mathrm{n}=319$ ), PFS was significantly prolonged with afatinib compared with gefitinib, although the difference in median PFS was only small. ${ }^{51}$ ORR was also significantly higher with afatinib (Table 1),

B

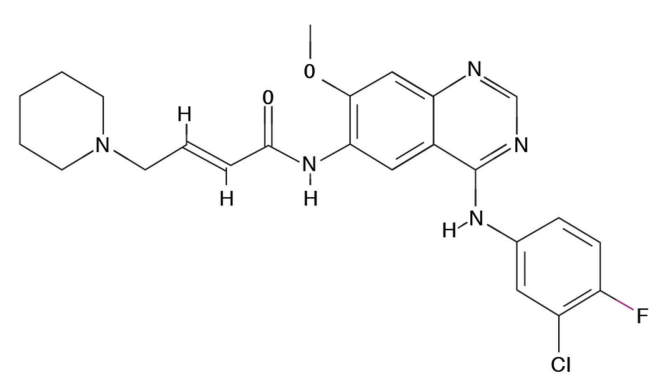

Figure I Chemical structures of (A) afatinib and (B) dacomitinib. 


\begin{tabular}{|c|c|c|c|c|c|c|c|c|c|c|c|c|c|c|}
\hline 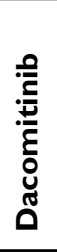 & 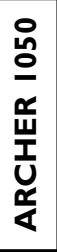 & $m$ & 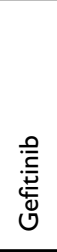 & 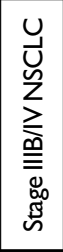 & 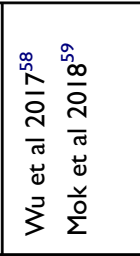 & E & ช্ & 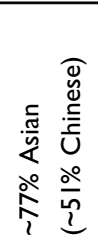 & 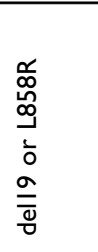 & 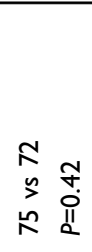 & 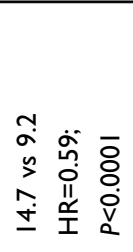 & 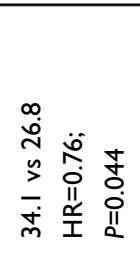 & 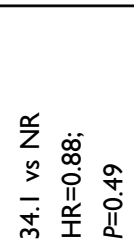 & 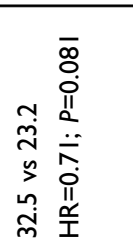 \\
\hline & 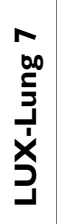 & กิ & 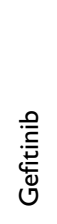 & 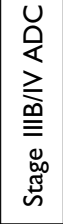 & 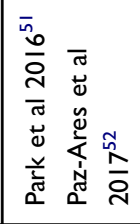 & $E$ & $\frac{\sigma}{m}$ & 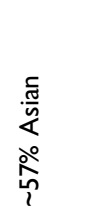 & 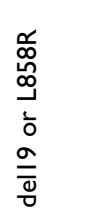 & 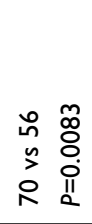 & 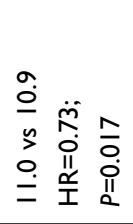 & 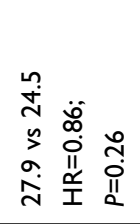 & 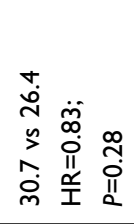 & 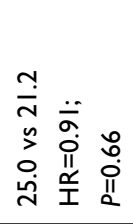 \\
\hline & & & & & 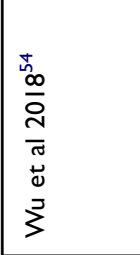 & 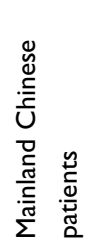 & $\widehat{্}$ & 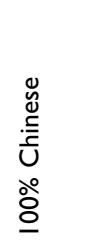 & 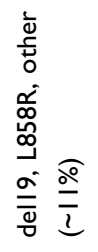 & 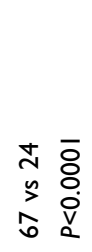 & 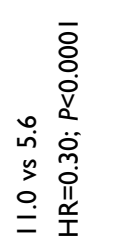 & 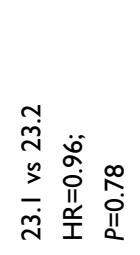 & 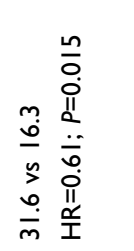 & 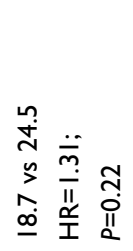 \\
\hline & 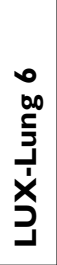 & $m$ & 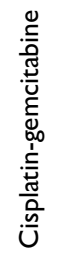 & 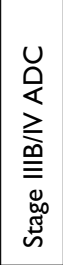 & 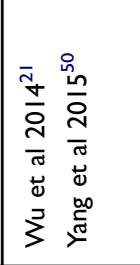 & $E$ & 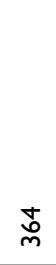 & 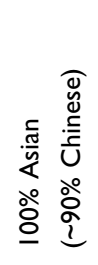 & 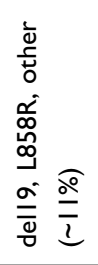 & 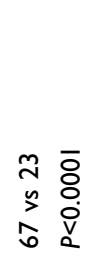 & 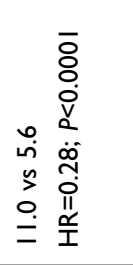 & 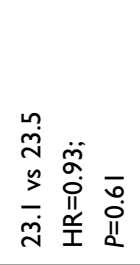 & 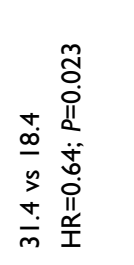 & 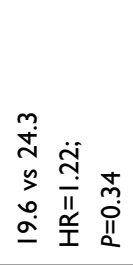 \\
\hline & & & & & 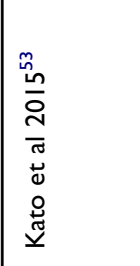 & 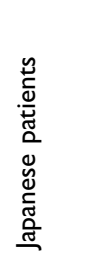 & $\varlimsup_{\infty}^{\infty}$ & 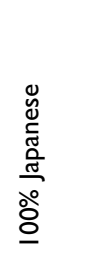 & 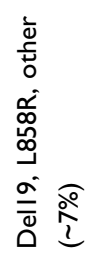 & $\begin{array}{ll}\bar{N} & \hat{o} \\
\text { s } \\
\overline{0} \\
\overline{0}\end{array}$ & 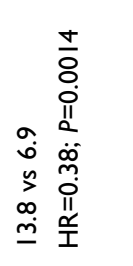 & 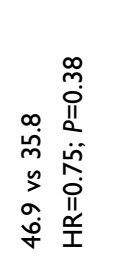 & 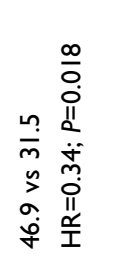 & 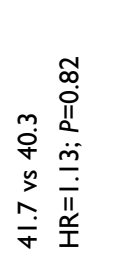 \\
\hline 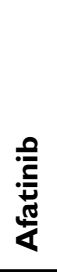 & 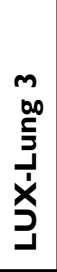 & $m$ & 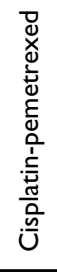 & 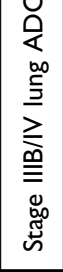 & 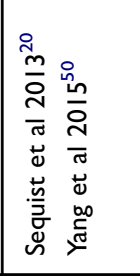 & $E$ & 占 & 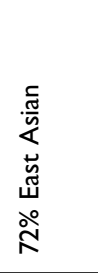 & 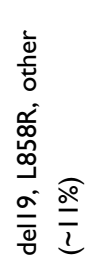 & 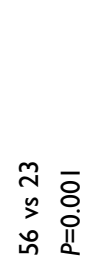 & 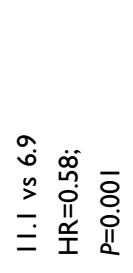 & 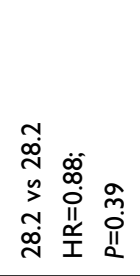 & 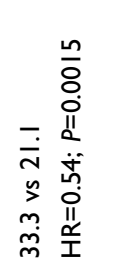 & 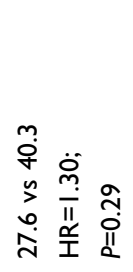 \\
\hline 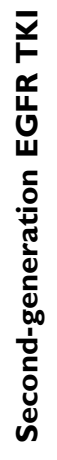 & 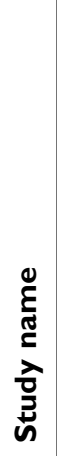 & 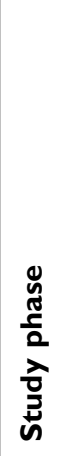 & 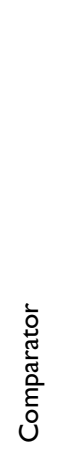 & 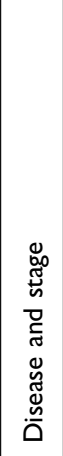 & 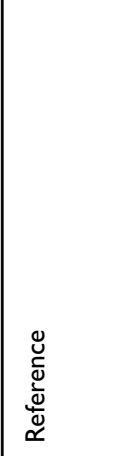 & $\begin{array}{l}\frac{n}{n} \\
\frac{\pi}{\bar{n}} \\
\frac{\tilde{c}}{\alpha}\end{array}$ & 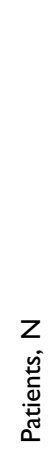 & 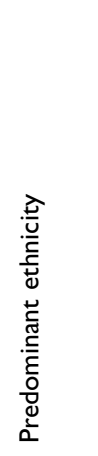 & 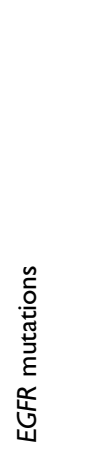 & 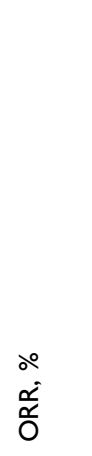 & 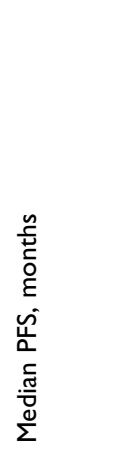 & 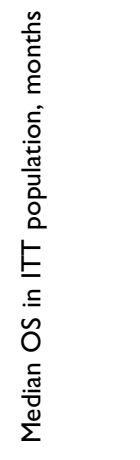 & 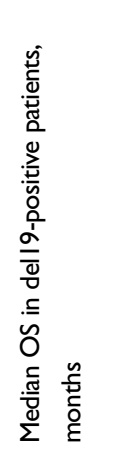 & 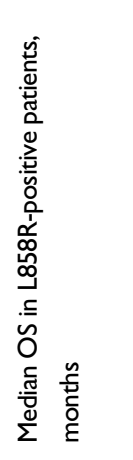 \\
\hline
\end{tabular}


A

\begin{tabular}{lcc} 
& $\begin{array}{c}\text { Afatinib } \\
(\mathrm{n}=203)\end{array}$ & $\begin{array}{c}\text { Pemetrexed-cisplatin } \\
(\mathrm{n}=104)\end{array}$ \\
\hline Median, months & 31.6 & 28.2 \\
$(95 \% \mathrm{Cl})$ & $(26.7-35.3)$ & $(20.6-32.3)$ \\
$\mathrm{HR}(95 \% \mathrm{Cl})$ & \multicolumn{2}{c}{$0.78(0.58-1.06)$} \\
$P$ value & \multicolumn{2}{c}{0.11}
\end{tabular}

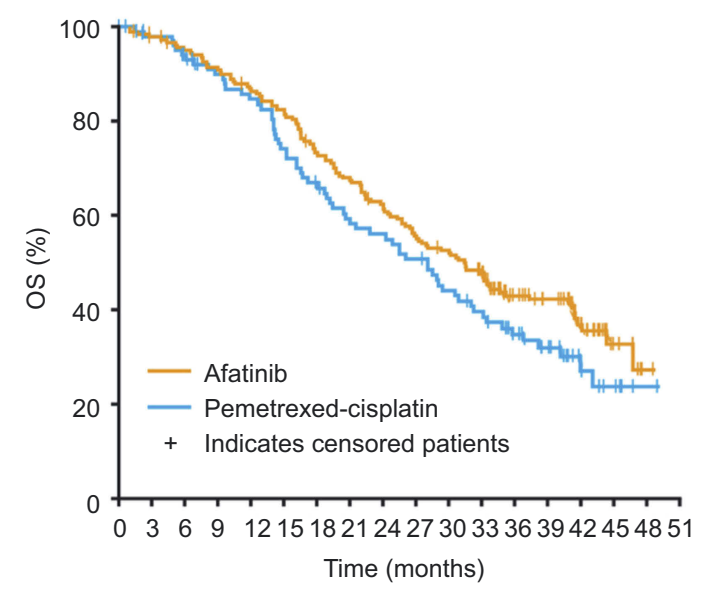

Number at risk

Afatinib $\quad 20319718818117116214313312110810190 \quad 5849 \quad 32 \quad 9 \quad 1 \quad 0$

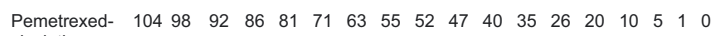
cisplatin
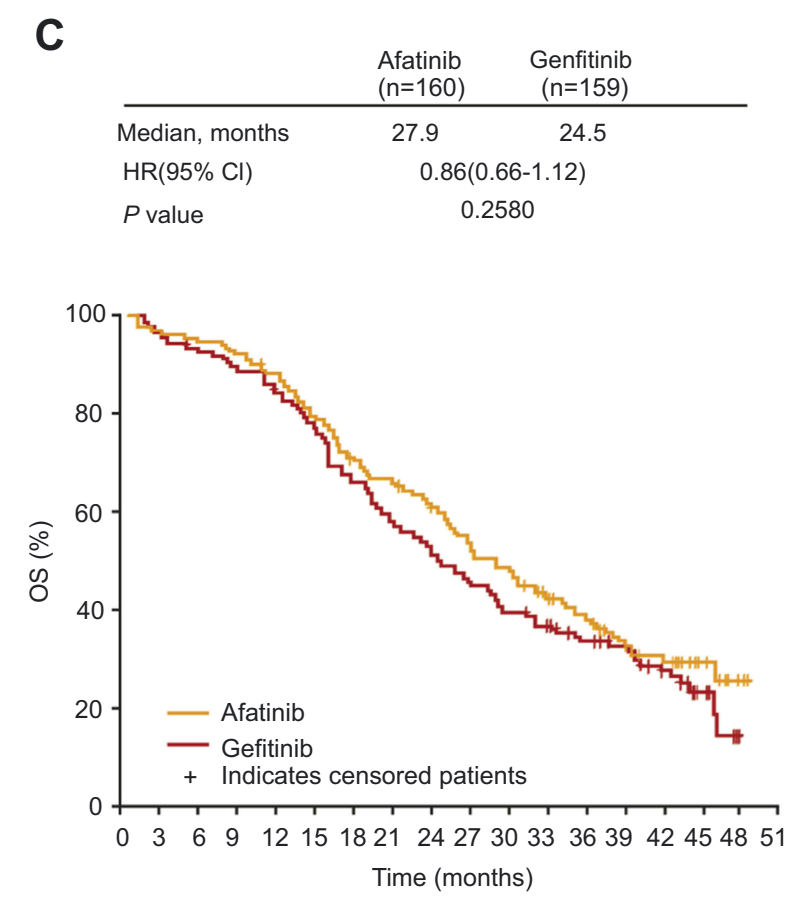

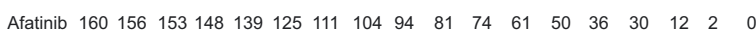

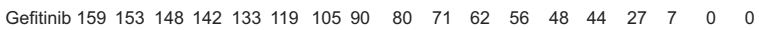

\begin{tabular}{llc} 
B & $\begin{array}{c}\text { Afatinib } \\
(\mathrm{n}=216)\end{array}$ & $\begin{array}{c}\text { Gemctabine-cisplatin } \\
(\mathrm{n}=108)\end{array}$ \\
\cline { 2 - 3 } Median, months & 23.6 & 23.5 \\
$(95 \% \mathrm{Cl})$ & $(20.5-28.5)$ & $(17.8-25.4)$ \\
$\mathrm{HR}(95 \% \mathrm{Cl})$ & \multicolumn{2}{c}{$0.83(0.62-1.09)$} \\
$P$ value & \multicolumn{2}{c}{0.18}
\end{tabular}

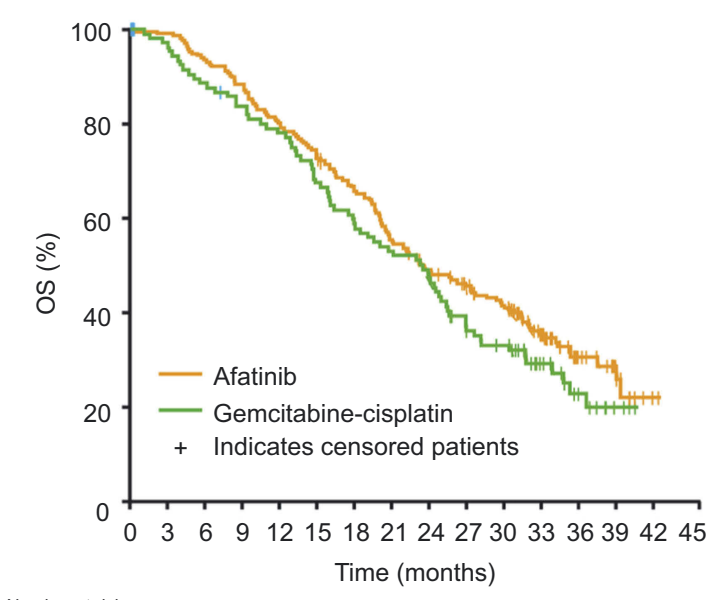

Number at risk

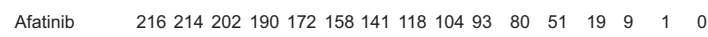

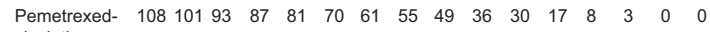
cisplatin

D

\begin{tabular}{cc}
$\begin{array}{c}\text { Dacomitinib } \\
(\mathrm{n}=227)\end{array}$ & $\begin{array}{c}\text { Gefitinib } \\
(\mathrm{n}=225)\end{array}$ \\
\hline
\end{tabular}
Median, months(95\% Cl) $34.1(29.5-37.7) \quad 26.8(23.7-32.1)$ $\mathrm{HR}(95 \% \mathrm{Cl}) \quad 0.760(0.582-0.993)$ $P$ value 0.0438

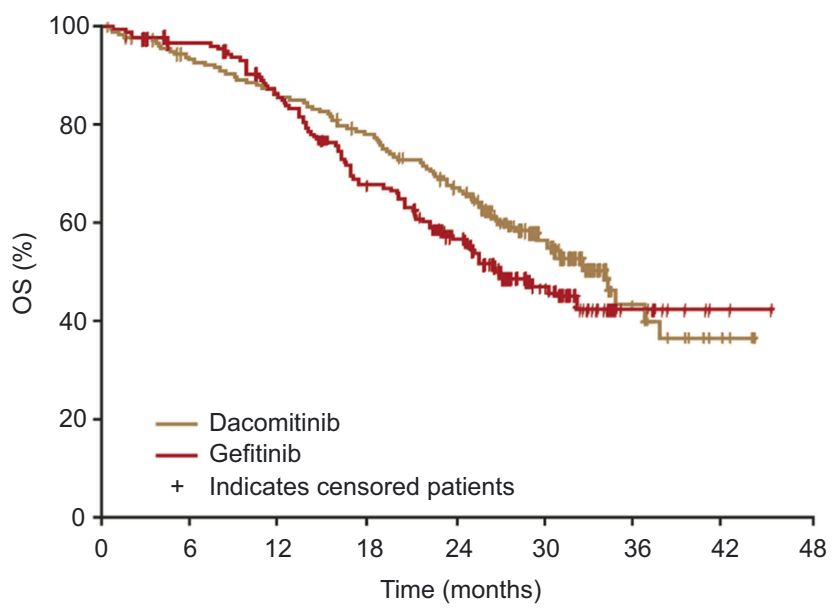

Number at risk:

$\begin{array}{lllllllll}\text { Dacomitinib } 227 & 206 & 188 & 167 & 138 & 77 & 14 & 3 & 0\end{array}$

Figure 2 Overall survival LUX-Lung 3 and LUX-Lung 6 (patients with Dell 9 and L858R mutations) and LUX-Lung 7 and ARCHER I050. (A) LUX-Lung 3; (B) LUX-Lung 6. Reprinted from The Lancet Oncology, I6(2), Yang JC, Wu YL, Schuler M, et al, Afatinib versus cisplatin-based chemotherapy for EGFR mutation-positive lung adenocarcinoma (LUXLung 3 and LUX-Lung 6): analysis of overall survival data from two randomised, phase 3 trials, $141-151$, Copyright @ 2015, with permission from Elsevier. ${ }^{50}$ (C) LUX-Lung 7. Reproduced from Paz-Ares L, Tan EH, O'Byrne K, et al, Afatinib versus gefitinib in patients with EGFR mutation-positive advanced non-small-cell lung cancer: overall survival data from the phase llb LUX-Lung 7 trial, Ann Oncol, 2017, 28(2), 270-277, by permission of Oxford University Press. ${ }^{52}$ (D) ARCHER 1050. Reprinted with permission. @ 2018 American Society of Clinical Oncology. All rights reserved. Mok TS, Cheng Y, Zhou X, et al, Improvement in overall survival in a randomized study that compared dacomitinib with gefitinib in patients with advanced non-small-cell lung cancer and EGFR-activating mutations, J Clin Oncol, 36(22), 2244-2250.59 
with a longer median duration of response for patients treated with afatinib than gefitinib (10.1 vs 8.4 months; $P$ not reported). In a subsequent survival analysis, there was no significant difference in OS, although median OS was numerically higher with afatinib vs gefitinib (Table 1; Figure 2C). ${ }^{52}$

In a pre-specified subgroup analysis, OS in both LUX-Lung 3 and LUX-Lung 6 was significantly longer with afatinib than chemotherapy in patients harboring the del19 EGFR mutation $(P<0.05)$, but not in those with the L858R mutation (Figure $3 \mathrm{~A}$ and B). ${ }^{50}$ Similar findings were reported in a sub-analysis of 83 Japanese patients from LUX-Lung $3^{53}$ and in a sub-analysis of 327 patients from mainland China enrolled in the LUXLung 6 study (Table 1). ${ }^{54}$ In LUX-Lung 7, there was no significant difference in OS between afatinib and gefitinib in patients with del19 mutations (Table 1; Figure 3C).

As a result of the above studies, afatinib is approved as first-line treatment of patients with advanced/metastatic
A

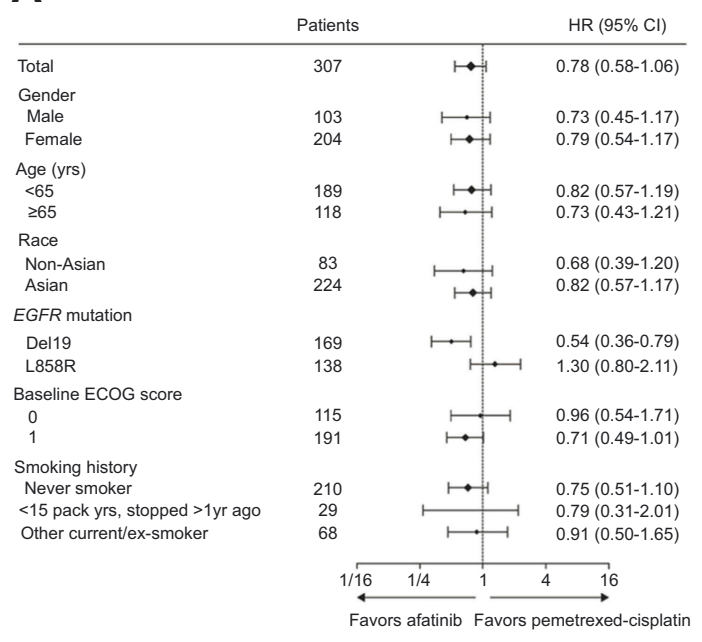

B

\begin{tabular}{|c|c|c|c|}
\hline & Patients & & $\mathrm{HR}(95 \% \mathrm{Cl})$ \\
\hline Total & 324 & $1+4$ & $0.83(0.63-1.09)$ \\
\hline \multicolumn{4}{|l|}{ Gender } \\
\hline Male & 111 & $\longmapsto$ & $0.70(0.44-1.11)$ \\
\hline Female & 213 & $\mapsto-1$ & $0.88(0.62-1.25)$ \\
\hline \multicolumn{4}{|l|}{ Age (yrs) } \\
\hline$<65$ & 246 & $\mapsto-1$ & $0.87(0.64-1.20)$ \\
\hline & 78 & $\longmapsto$ & $0.60(0.33-1.10)$ \\
\hline \multicolumn{4}{|l|}{ EGFR mutation } \\
\hline Del19 & 186 & $\mapsto-1$ & $0.64(0.44-0.94)$ \\
\hline L858R & 138 & $\mapsto \cdot 1$ & $1.22(0.81-1.83)$ \\
\hline \multicolumn{4}{|l|}{ Baseline ECOG score } \\
\hline 0 & 78 & $\longmapsto$ & $1.82(0.48-1.38)$ \\
\hline 1 & 246 & $\mapsto-1$ & $1.83(0.59-1.16)$ \\
\hline \multicolumn{4}{|l|}{ Smoking history } \\
\hline Never smoker & 251 & $\mapsto-1$ & $0.71(0.52-0.97)$ \\
\hline$<15$ pack yrs, stopped >1yr ago & 11 & & $-11.22(0.31-4.80)$ \\
\hline \multirow[t]{2}{*}{ Other current/ex-smoker } & 62 & $\longmapsto$ & $1.29(0.65-2.57)$ \\
\hline & $1 / 16$ & $1 / 4$ & 16 \\
\hline
\end{tabular}
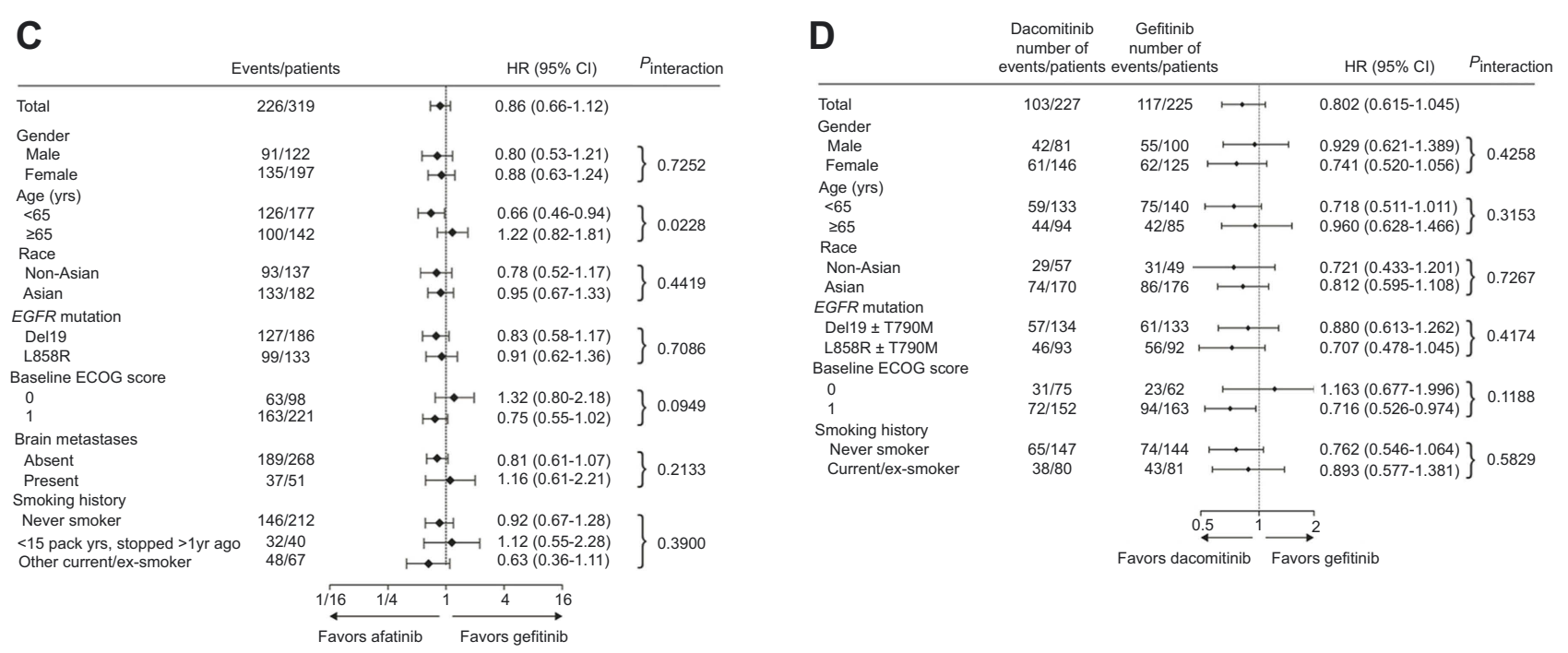

Figure 3 Subgroup analyses of overall survival in (A) in LUX-Lung 3 (dell 9 and L858R mutations only). (B) LUX-Lung 6 (dell 9 and L858R mutations only). Reprinted from The Lancet Oncology, I6(2), Yang JC, Wu YL, Schuler M, et al, Afatinib versus cisplatin-based chemotherapy for EGFR mutation-positive lung adenocarcinoma (LUXLung 3 and LUX-Lung 6): analysis of overall survival data from two randomised, phase 3 trials, |4I-I5I, Copyright @ 20I5, with permission from Elsevier. ${ }^{50}$ (C) LUXLung 7. Reproduced from Paz-Ares L, Tan EH, O'Byrne K, et al, Afatinib versus gefitinib in patients with EGFR mutation-positive advanced non-small-cell lung cancer: overall survival data from the phase Ilb LUX-Lung 7 trial, Ann Oncol, 2017, 28(2), 270-277, by permission of Oxford University Press. ${ }^{52}$ (D) ARCHER I050. Reprinted with permission. (C) 2018 American Society of Clinical Oncology. All rights reserved. Mok TS, Cheng Y, Zhou X, et al, Improvement in overall survival in a randomized study that compared dacomitinib with gefitinib in patients with advanced non-small-cell lung cancer and EGFR-activating mutations, J Clin Oncol, 36(22), 2244-2250. ${ }^{59}$ Abbreviations: ECOG, Eastern Cooperative Oncology Group; PS performance status. 
NSCLC whose tumors have nonresistant EGFR mutations. ${ }^{55,56}$

\section{Dacomitinib}

The first clinical study of dacomitinib in a first-line setting was a Phase II, single-arm study that recruited patients with advanced NSCLC who were never- or former light smokers, and/or who were EGFR mutation-positive. The 4-month PFS rate was $77 \%$ in all 89 dacomitinib-treated patients and $96 \%$ in the 45 patients with $E G F R$ mutations. ${ }^{57}$ This study paved the way for the Phase III ARCHER 1050 study, in which 452 EGFR TKI-naïve patients with newly diagnosed or recurrent $(\geq 12$ months since prior treatment) NSCLC received either dacomitinib or gefitinib (Table 1). ${ }^{58}$ Median PFS was significantly longer with dacomitinib than gefitinib, although ORR was similar (Table 1). In patients who responded to treatment, however, duration of response was longer in the dacomitinib group (14.8 vs 8.3 months; $P<0.0001)$. Further, although not a formal analysis due to hierarchical testing, an OS benefit was observed with dacomitinib (Table 1; Figure 2D). ${ }^{59}$ Interestingly, OS in the subgroup of patients with exon 19 deletions was similar in both treatment arms (Table 1; Figure 3D), whereas median OS was longer with dacomitinib in patients with L858R mutations, although the difference was not significant (Table 1). Pre-specified subgroup analyses of PFS suggest that dacomitinib may be more beneficial in Asian patients $(\mathrm{HR}=0.51)$ than in non-Asian patients $(\mathrm{HR}=0.89)$. On the basis of the ARCHER 1050 results, dacomitinib has been approved by both the US FDA and the European Medicines Agency for the first-line treatment of EGFRmutated metastatic NSCLC.

While cross-trial comparisons should be avoided, it should be noted that both the study populations and the study designs of LUX-Lung 7 and ARCHER 1050 differed. In LUX-Lung 7, approximately $16 \%$ of patients had baseline central nervous system (CNS) metastases, whereas such patients were excluded from ARCHER $1050 .^{51,58}$ In addition, LUX-Lung 7 was a smaller, Phase IIb study and was underpowered to detect an OS difference.

\section{Meta-analysis}

A network meta-analysis compared erlotinib, gefitinib, icotinib, afatinib, and dacomitinib using data from six head-tohead Phase III studies in patients with advanced EGFR mutation-positive NSCLC. ${ }^{60}$ While the five TKIs were found to have similar therapeutic efficacy in terms of all outcome measures (ORR, disease control rate, 1-year PFS, 1-year OS, and 2-year OS), rank probabilities indicated a preferable therapeutic efficacy for the second-generation TKIs relative to the first-generation TKIs. When compared with other agents, potential survival benefits (PFS and OS) were observed with dacomitinib, while afatinib had a higher rank probability in terms of ORR and disease control. The superiority of second-generation versus first-generation TKIs was also demonstrated in a recent meta-analysis including data from 18 randomized controlled trials and 20 retrospective cohort studies, with prolonged pooled PFS and OS reported with second-generation TKIs in the pooled dataset. $^{61}$ This superiority was demonstrated for patients with del19 and those with L858R mutations.

\section{Clinical efficacy in the real-world setting}

Importantly, real-world studies support the findings from the pivotal Phase III studies and demonstrated the efficacy of afatinib in routine clinical practice. Several retrospective analyses have compared afatinib with first-generation TKIs in Asian populations, ${ }^{62-65}$ while others report the use of afatinib only. ${ }^{11,66-69}$ Median PFS ranged from around 12 months up to 19 months; in some comparative studies, afatinib was associated with significantly prolonged PFS vs both gefitinib and erlotinib, ${ }^{63,65}$ but only gefitinib in others. ${ }^{64}$ In a retrospective, population-based study of 467 patients with advanced NSCLC in South Korea, median PFS was 19.1 months with afatinib, compared with 13.7 and 14.0 months with gefitinib and erlotinib, respectively $(P=0.001) .{ }^{63}$ In this study, the benefit of afatinib was more pronounced in patients with del19 or uncommon EGFR mutations. A Canadian retrospective analysis also reported a survival benefit with second-generation compared with first-generation TKIs in patients with del19 mutations. ${ }^{70}$ Data from a broad Asian population $(n=479)$ in a large, Phase IIIb expanded access study, conducted in a setting similar to real-world practice, have further demonstrated the efficacy of afatinib in patients with common or uncommon EGFR mutations, with a median PFS of 12.1 months and time to symptomatic progression of 15.3 months. ${ }^{69}$

\section{First-line clinical efficacy in patient subgroups}

While the pivotal clinical studies provide invaluable information on the use of afatinib and dacomitinib in broad clinical trial populations, certain patient subgroups that are frequently encountered in routine clinical practice may be excluded 
from these trials due to strict inclusion or exclusion criteria. This includes patients whose tumors harbor uncommon mutations, those with brain metastases, and patients of advanced age. Fortunately, an increasing number of real-world studies are being reported, particularly on the real-world use of afatinib, providing a more detailed picture in these patient populations.

\section{Patients with uncommon mutations}

While common EGFR mutations (del19 and L858R) are highly sensitive to EGFR TKIs, certain uncommon mutations may be less sensitive, with lower response rates and/ or shorter survival reported in many studies. ${ }^{17,18,71-75}$ However, studies suggest that some uncommon EGFR mutations, such as exon 19 insertions, L861Q, G719X, and S768I, are sensitive to certain TKIs, with response rates varying from $42 \%$ to $57 \%$ depending on the mutation and the TKI. ${ }^{18,71,72,76,77}$

In preclinical studies, cells harboring certain nonclassical EGFR mutations, including L861Q, S768I, and G719A, were sensitive to treatment with afatinib; in contrast, sensitivity was markedly lower with erlotinib and gefitinib. ${ }^{78-80}$ The clinical efficacy of afatinib in patients with uncommon mutations was assessed in a pooled posthoc analysis of the LUX-Lung 2 (single arm, Phase II trial in EGFR mutation-positive patients with $\leq 1$ prior treatment), ${ }^{81}$ LUX-Lung 3, and LUX-Lung 6 studies and demonstrated that response and survival following afatinib treatment were highest in patients with point mutations or duplications in exons $18-21$ and lowest in patients with exon 20 insertions. $^{25}$ In patients with the most frequent uncommon mutations, the ORR varied according to the mutation (78\% G719X; 56\% L861Q; 100\% S768I) but was generally comparable to, or higher than, that seen in the overall study populations.

Findings from a retrospective, population-based study of patients with advanced NSCLC receiving first-line TKI therapy suggested that overall response may be higher with afatinib than with gefitinib or erlotinib in patients with uncommon mutations, ${ }^{63}$ while in another retrospective analysis, PFS was numerically longer with afatinib than gefitinib or erlotinib in patients with uncommon EGFR mutations (median 19.7 vs 7.0 vs 7.0 months, respectively; $P=0.506) .{ }^{65}$ A small retrospective study involving patients with advanced NSCLC and uncommon EGFR mutations, $89 \%$ of whom were receiving first-line treatment, reported significantly longer PFS in patients treated with afatinib compared with erlotinib/gefitinib (median: 11.0 vs 3.6 months; $P=0.03) .{ }^{11}$ In 24 patients with G719X, S768I, or L861Q mutations, median PFS was 18.3 months with afatinib and 2.6 months for both erlotinib and gefitinib. Subsequent to these reports, and on the basis of the results from the LUX-Lung 2, 3, and 6 trials, the United States FDA approval for afatinib was extended to include patients with these mutations. 54

As the ARCHER 1050 study only included patients with common mutations (del19 or L858R), and no realworld data are available as yet, the efficacy of dacomitinib in patients with uncommon mutations is currently uncertain.

\section{Older patients}

The LUX-Lung 3, LUX-Lung-6, and LUX-Lung 7 studies all permitted the enrolment of patients aged $>65$ years and thus provide valuable data on the agent's efficacy and safety in older individuals. In prespecified analyses in LUX-Lung 3 and LUX-Lung 6, median PFS was prolonged with afatinib compared with chemotherapy in the subgroup of patients aged $\geq 65$ years (LUX-Lung 3 : $n=134$, median 11.3 vs 8.2 months, $\mathrm{HR}=0.64 ; 95 \% \mathrm{CI}=0.39-1.03$; LUX-Lung 6: $\mathrm{n}=86$, median 13.7 vs 4.1 months, $\mathrm{HR}=0.16$; $95 \% \mathrm{CI}=0.07-0.39$ ) as well as in younger patients (LUXLung 3: 11.0 vs 5.8 months, $\mathrm{HR}=0.53 ; 95 \% \mathrm{CI}=0.36-0.76$; LUX-Lung 6: 11.0 vs 5.6 months, $\mathrm{HR}=0.30 ; 95 \%$ $\mathrm{CI}=0.21-0.43) .{ }^{82}$ In LUX-Lung 7, median PFS with afatinib was the same (11.0 months) in patients aged $<65$ years and those aged $\geq 65$ years. ${ }^{51}$ In patients aged $\geq 65$ years in LUX-Lung 3 and LUX-Lung 6, there was a trend toward improved OS with afatinib vs chemotherapy in the overall study populations, and in those with common EGFR mutations (del19/L858R); of note, in LUX-Lung 3, the OS difference was significant for elderly patients with del19 mutations $(41.5$ vs 14.3 months; $\mathrm{HR}=0.39 ; 95 \%$ $\mathrm{CI}=0.19-0.80) .{ }^{82}$ Exploratory analyses of patients aged $\geq 75$ years in LUX-Lung 7 demonstrated a trend toward improved PFS with afatinib vs gefitinib (median 14.7 vs 10.8 months; $\mathrm{HR}=0.69 ; 95 \% \mathrm{CI}=0.33-1.44)$, consistent with the overall population and the younger subgroup. Median OS with afatinib or gefitinib was 27.9 vs 19.7 months $(\mathrm{HR}=1.05 ; 95 \% \mathrm{CI}=0.50-2.21)$ in patients aged $\geq 75$ years and 28.9 vs 25.2 months $(\mathrm{HR}=0.85$; 95\% $\mathrm{CI}=0.64-1.12)$ in patients aged $<75$ years. In a singlearm, open-label, Phase IIIb study of Asian patients with EGFR mutation-positive NSCLC treated with first-line afatinib, median PFS was longer in patients aged $\geq 65$ years compared with those aged $<65$ years. ${ }^{69}$ Similarly, 
real-world data from the observational GioTag study demonstrated no difference in time on afatinib treatment in patients aged $<65$ years vs those aged $\geq 65$ years $(11.8$ vs 12.2 months, $P=0.241){ }^{83}$

In the ARCHER 1050 study, subgroup analyses of PFS suggest that dacomitinib may be more effective in patients aged $<65$ years $(\mathrm{HR}=0.51 ; 95 \% \mathrm{CI}=0.39-0.69)$ than in patients aged $\geq 65$ years $(\mathrm{HR}=0.69 ; 95 \% \mathrm{CI}=0.48-0.99) .{ }^{58}$

\section{Patients with brain metastases}

Brain metastases are common in NSCLC, being identified at diagnosis in at least $10 \%$ of all patients and around one-quarter of patients with EGFR mutation-positive NSCLC. ${ }^{84,85}$ Cumulative incidence rises over time, increasing to almost $50 \%$ in EGFR mutation-positive patients 3 years postdiagnosis. ${ }^{84}$ Afatinib has been shown to penetrate the bloodbrain barrier in mice ${ }^{86}$ and in human subjects, with the concentration seen in the cerebrospinal fluid being well above the $\mathrm{IC}_{50}$ of afatinib against EGFR in in vitro studies. ${ }^{87-89}$ A combined subgroup analysis of LUX-Lung 3 and LUXLung 6 demonstrated that among 81 patients with asymptomatic brain metastases at baseline, PFS was significantly improved with afatinib vs chemotherapy (8.2 vs 5.4 months; $\mathrm{HR}=0.50 \quad[95 \% \mathrm{CI}=0.52-0.95] ; P=0.0297) .{ }^{90}$ Further, the magnitude of PFS improvement with afatinib was similar to that observed in patients without brain metastases (LUX-Lung 3: $\mathrm{HR}=0.54$ vs 0.48 ; LUX-Lung 6: $\mathrm{HR}=0.47$ vs 0.22 ). Also, in both studies, ORR was significantly higher with afatinib than chemotherapy in patients with brain metastases. There were, however, no significant differences in OS between the afatinib and chemotherapy groups. A competing risk analysis using data from afatinib-treated patients with baseline brain metastases in LUX-Lung 3, LUX-Lung 6, and LUX-Lung 7 showed that the cumulative incidence of CNS progression (31\%) was lower than that of non-CNS progression $(52 \%){ }^{91}$ Furthermore, the risk of de novo CNS progression with afatinib was very low, being observed in only $6 \%$ of patients who received afatinib in LUX-Lung 3 and LUX-Lung 6. Non-CNS progression for patients without baseline brain metastases was $78 \%$.

Observations of CNS activity with afatinitib in clinical trials are supported by a number of real-world studies. For example, data from a small retrospective review of 28 treatment-naïve patients with EGFR mutation-positive lung adenocarcinoma and brain metastases suggests that afatinib leads to comparable OS and time to treatment failure when given alone or in combination with whole-brain radiotherapy. ${ }^{92}$
ORR was over $80 \%$ for both treatment groups. Another analysis of data from 29 Korean patients with recurrent or metastatic NSCLC and brain metastases who received the first-line afatinib reported a $76 \%$ response rate to afatinib monotherapy and a median PFS of 15.7 months. ${ }^{93}$ In a real-world study conducted in Singapore in patients with brain metastases prior to starting therapy, a lower afatinib starting dose $(30 \mathrm{mg})$ was associated with significantly shorter PFS than a $40 \mathrm{mg}$ starting dose (median: 5.3 vs 13.3 months; $P=0.04){ }^{67}$ This may suggest that higher doses are required to achieve therapeutic levels within the CNS but may also simply be reflective of the subgroup of patients selected to receive a lower starting dose in this real-world study.

As patients with brain metastases were excluded from the ARCHER 1050 trial, no data on the CNS efficacy of dacomitinib are currently available.

\section{Resistance mechanisms and subsequent treatment options}

As with the first-generation TKIs, resistance eventually develops to both afatinib and dacomitinib. T790M appears to be the key resistance mechanism to afatinib, being detected in 43-68\% of patients from primarily Asian populations $^{94-96}$ and $73 \%$ of Caucasian patients ${ }^{97}$ after afatinib failure. Other resistance mutations developing in the EGFR gene in response to afatinib include the C797S and L792F mutations and MET amplification, which have been observed in vitro. ${ }^{98}$ Although the mechanisms of resistance to dacomitinib have not been as well characterized, in vitro data suggest that resistance to dacomitinib therapy primarily involves T790M mutations and, less frequently, C797S mutations. ${ }^{98}$

The third-generation TKI, osimertinib, is selective for both EGFR-sensitizing and EGFR T790M-resistance mutations and is approved for use in both the firstand second-line settings in metastatic NSCLC. ${ }^{99}$ In the Phase III FLAURA study, PFS was significantly prolonged in patients with L858R or del19 EGFR mutations receiving the first-line osimertinib compared with firstgeneration TKIs (18.9 vs 10.2 months; $P<0.001),{ }^{100}$ and in a network meta-analysis, PFS appeared longer with the first-line osimertinib than erlotinib, gefitinib, afatinib, and dacomitinib. ${ }^{101}$ However, no clear resistance mutation to the first-line osimertinib has been identified, limiting options for subsequent therapy. ${ }^{102}$

In patients with T790M-positive advanced NSCLC who had progressed after first-line TKI therapy, 
osimertinib was associated with significantly longer PFS than patients who received platinum-pemetrexed (median: 10.1 vs 4.4 months; $P<0.001) .{ }^{103}$ Thus, osimertinib is an effective option after the failure of first- or secondgeneration TKIs to extend the duration of the therapeutic benefit obtained with targeted therapies. Encouraging OS results from 37 patients in the LUX-Lung 3, LUX-Lung 6, and LUX-Lung 7 trials who received osimertinib after afatinib, where median time on treatment was 20.2 months and median OS had not been reached after $>4$ years of follow-up, support the use of osimertinib in this setting. ${ }^{104}$ Further, in a multicenter observational study of 204 patients who received second-line osimertinib after developing the T790M mutation with the first-line afatinib, the overall median time on treatment was 27.6 months. ${ }^{83}$ However, further data are needed to determine the most appropriate sequential therapy and to determine whether osimertinib is best used upfront or reserved until after firstline TKI failure. The latter is a controversial topic following the first-line approval of osimertinib and in the context of the emerging challenge of osimertinib resistance. ${ }^{105-107}$

For patients who are T790M-negative and therefore not candidates for osimertinib, novel combinations of secondgeneration TKIs and other agents may overcome EGFR bypass mechanisms and provide alternative second-line options. Several agents have been tested in combination with afatinib, including cetuximab, ${ }^{108}$ paclitaxel, ${ }^{109}$ bevacizumab, ${ }^{110}$ and pembrolizumab (NCT02364609), but further investigation is required.

\section{Safety}

Adverse events (AEs) with second-generation TKIs are largely predictable and manageable, ${ }^{20,21,51,58}$ although occurring more frequently than with first-generation TKIs, ${ }^{51,58,111}$ likely reflecting the irreversible activity and broader inhibitory profile. Diarrhea and skin-related events such as acne or dryness, stomatitis, and paronychia were the most common AEs reported in pivotal clinical studies of afatinib and dacomitinib. ${ }^{20,21,51,57,58}$ Similar AEs have been reported in large real-world studies of afatinib (diarrhea, rash/acne, stomatitis, and paronychia), ${ }^{63,67,69}$ further demonstrating the predictable nature of these AEs. In a sub-analysis of the LUX-Lung 3, LUX-Lung 6, and LUX-Lung 7 studies, afatinib-associated AEs in older patients were consistent with the overall populations. ${ }^{82}$ Of note, afatinib-related AEs can be controlled with tolerability-guided dose reductions that do not impact efficacy. ${ }^{63,65,66,68,112,113}$ For example, in a Korean real- world study, substantially more patients receiving afatinib required dose reductions compared with gefitinib and erlotinib; however, dose reductions did not adversely affect PFS in afatinib-treated patients (median: 23.5 vs 12.4 months for dose-reduced vs non-dose-reduced patients). ${ }^{63}$

Improvement in patient-reported outcomes such as time to deterioration of symptoms, cough, dyspnea, and pain symptoms, as well as overall health and quality of life, were reported for patients receiving afatinib relative to chemotherapy in the LUX-Lung 3 and LUX-Lung 6 studies. $^{20,21}$ In LUX-Lung 7, similar improvements in health status, as assessed by the EuroQoL-5D health status self-assessment questionnaire and the EuroQoL visual ana$\log$ scale, were reported for afatinib and gefitinib. In ARCHER 1050, the improvement in global quality of life was significantly greater with gefitinib versus dacomitinib, although neither improvement was considered clinically meaningful. ${ }^{58}$ In individual symptom scales, dacomitinib was associated with a greater improvement from baseline versus gefitinib in cough and chest pain symptoms, but a significant worsening in diarrhea and sore mouth symptoms.

\section{Conclusions}

Second-generation TKIs have demonstrated improved efficacy vs first-generation TKIs and are an effective first-line therapeutic option for patients with advanced NSCLC, including Asian patients. As the number of therapeutic options for advanced NSCLC increases, the choice of first-line treatment will be determined by considering patient factors such as the presence of brain metastases, the type of EGFR mutation, tolerability, and subsequent therapy options for long-term treatment. In most clinical trials to date, the secondgeneration TKIs have been associated with manageable toxicity profiles and superior outcomes compared with first-generation TKIs, most likely due to their broader inhibitory profile. With striking efficacy in the first-line setting recently shown with the third-generation TKI, osimertinib, an important goal of future studies will be determining the optimal sequencing of the first-, second-, and third-generation TKIs to maximize patient response and survival across all lines of therapy.

\section{Acknowledgments}

Writing and editorial support was provided by Jane Saunders, of GeoMed, an Ashfield Company, part of UDG Healthcare plc, which was contracted and funded 
by Boehringer Ingelheim. Funding for the development of this manuscript was provided by Boehringer Ingelheim. Boehringer Ingelheim were given the opportunity to review the manuscript for medical and scientific accuracy, as well as for intellectual property considerations.

\section{Disclosure}

The authors report a grant from Boehringer Ingelheim. The authors report no other conflicts of interest in this work.

\section{References}

1. Organization WH. Cancer (factsheet). Available from: http://www. who.int/news-room/fact-sheets/detail/cancer (Accessed 28 June 2018). 2018.

2. Novello S, Barlesi F, Califano R, et al. Metastatic non-small-cell lung cancer: ESMO clinical practice guidelines for diagnosis, treatment and follow-up. Ann Oncol. 2016;27(suppl 5):v1-v27. doi:10.1093/annonc/mdw326

3. Solomon BJ, Mok T, Kim DW, et al. First-line crizotinib versus chemotherapy in ALK-positive lung cancer. $N$ Engl $J$ Med. 2014;371(23):2167-2177. doi:10.1056/NEJMoa1408440

4. Pao W, Miller V, Zakowski M, et al. EGF receptor gene mutations are common in lung cancers from "never smokers" and are associated with sensitivity of tumors to gefitinib and erlotinib. Proc Natl Acad Sci U S A. 2004;101(36):13306-13311. doi:10.1073/ pnas. 0405220101

5. Rosell R, Moran T, Queralt C, et al. Screening for epidermal growth factor receptor mutations in lung cancer. $N$ Engl $J$ Med. 2009;361(10):958-967. doi:10.1056/NEJMoa0904554

6. Siegelin MD, Borczuk AC. Epidermal growth factor receptor mutations in lung adenocarcinoma. Lab Invest. 2014;94(2):129-137. doi:10.1038/labinvest.2013.147

7. Roskoski R Jr. The ErbB/HER family of protein-tyrosine kinases and cancer. Pharmacol Res. 2014;79:34-74. doi:10.1016/j. phrs.2013.11.002

8. Zhang H, Berezov A, Wang Q, et al. ErbB receptors: from oncogenes to targeted cancer therapies. J Clin Invest. 2007;117 (8):2051-2058. doi:10.1172/JCI32278

9. Cancer Genome Atlas Research N. Comprehensive molecular profiling of lung adenocarcinoma. Nature. 2014;511(7511):543-550. doi:10.1038/nature13385

10. Cancer Genome Atlas Research Network. Comprehensive genomic characterization of squamous cell lung cancers. Nature. 2012;489 (7417):519-525. doi:10.1038/nature11404

11. Shen YC, Tseng GC, Tu CY, et al. Comparing the effects of afatinib with gefitinib or erlotinib in patients with advanced-stage lung adenocarcinoma harboring non-classical epidermal growth factor receptor mutations. Lung Cancer. 2017;110:56-62. doi:10.1016/j.lungcan.2017.06.007

12. Shi Y, Au JS, Thongprasert S, et al. A prospective, molecular epidemiology study of EGFR mutations in Asian patients with advanced non-small-cell lung cancer of adenocarcinoma histology (PIONEER). $\quad J$ Thorac Oncol. 2014;9(2):154-162. doi:10.1097/JTO.0000000000000033

13. Lu RL, Hu CP, Yang HP, et al. Biological characteristics and epidermal growth factor receptor tyrosine kinase inhibitors efficacy of EGFR mutation and its subtypes in lung adenocarcinoma. Pathol Oncol Res. 2014;20(2):445-451. doi:10.1007/s12253-013-9715-0
14. Kris MG, Johnson BE, Berry LD, et al. Using multiplexed assays of oncogenic drivers in lung cancers to select targeted drugs. Jama. 2014;311(19):1998-2006. doi:10.1001/jama.2014.3741

15. Lynch TJ, Bell DW, Sordella R, et al. Activating mutations in the epidermal growth factor receptor underlying responsiveness of non-small-cell lung cancer to gefitinib. $N$ Engl J Med. 2004;350 (21):2129-2139. doi:10.1056/NEJMoa040938

16. Mok TS, Wu YL, Thongprasert $\mathrm{S}$, et al. Gefitinib or carboplatin-paclitaxel in pulmonary adenocarcinoma. $N$ Engl J Med. 2009;361(10):947-957. doi:10.1056/NEJMoa0810699

17. Krawczyk P, Kowalski DM, Ramlau R, et al. Comparison of the effectiveness of erlotinib, gefitinib, and afatinib for treatment of non-small cell lung cancer in patients with common and rare EGFR gene mutations. Oncol Lett. 2017;13(6):4433-4444. doi:10.3892/ ol.2017.5980

18. Kuiper JL, Hashemi SM, Thunnissen E, et al. Non-classic EGFR mutations in a cohort of Dutch EGFR-mutated NSCLC patients and outcomes following EGFR-TKI treatment. Br J Cancer. 2016;115 (12):1504-1512. doi:10.1038/bjc.2016.372

19. Mitsudomi T, Yatabe Y. Mutations of the epidermal growth factor receptor gene and related genes as determinants of epidermal growth factor receptor tyrosine kinase inhibitors sensitivity in lung cancer. Cancer Sci. 2007;98(12):1817-1824. doi:10.1111/ j.1349-7006.2007.00607.x

20. Sequist LV, Yang JC, Yamamoto N, et al. Phase III study of afatinib or cisplatin plus pemetrexed in patients with metastatic lung adenocarcinoma with EGFR mutations. J Clin Oncol. 2013;31 (27):3327-3334. doi:10.1200/JCO.2012.44.2806

21. Wu YL, Zhou $\mathrm{C}, \mathrm{Hu} \mathrm{CP}$, et al. Afatinib versus cisplatin plus gemcitabine for first-line treatment of Asian patients with advanced non-small-cell lung cancer harbouring EGFR mutations (LUX-Lung 6): an open-label, randomised phase 3 trial. Lancet Oncol. 2014;15 (2):213-222. doi:10.1016/S1470-2045(13)70604-1

22. Keam B, Kim DW, Park JH, et al. Rare and complex mutations of epidermal growth factor receptor, and efficacy of tyrosine kinase inhibitor in patients with non-small cell lung cancer. Int $J$ Clin Oncol. 2014;19(4):594-600. doi:10.1007/s10147-013-0602-1

23. Beau-Faller M, Prim N, Ruppert AM, et al. Rare EGFR exon 18 and exon 20 mutations in non-small-cell lung cancer on 10117 patients: a multicentre observational study by the French ERMETIC-IFCT network. Ann Oncol. 2014;25(1):126-131. doi:10.1093/annonc/mdt418

24. Heigener DF, Schumann C, Sebastian M, et al. Afatinib in non-small cell lung cancer harboring uncommon EGFR mutations pretreated with reversible EGFR inhibitors. Oncologist. 2015;20 (10):1167-1174. doi:10.1634/theoncologist.2015-0073

25. Yang JC, Sequist LV, Geater SL, et al. Clinical activity of afatinib in patients with advanced non-small-cell lung cancer harbouring uncommon EGFR mutations: a combined post-hoc analysis of LUX-Lung 2, LUX-Lung 3, and LUX-Lung 6. Lancet Oncol. 2015;16(7):830-838. doi:10.1016/S1470-2045(15)00026-1

26. Solca F, Dahl G, Zoephel A, et al. Target binding properties and cellular activity of afatinib (BIBW 2992), an irreversible ErbB family blocker. $J$ Pharmacol Exp Ther. 2012;343(2):342-350. doi:10.1124/jpet.112.197756

27. TARCEVA ${ }^{\circledR}$ (erlotinib) tablets, oral [prescribing information]. San Francisco, CA: Genentech USA, Inc. Revised October 2016.

28. TARCEVA (Erlotinib) Tablets: Summary of Product Characteristics. Roche Pharma AG. Available from: https://www.ema.europa.eu/en/ documents/product-information/tarceva-epar-product-information_en. pdf. Accessed June 14, 2019.

29. IRESSA (gefitinib) tablets for oral use [prescribing information] Wilmington, DE: AstraZeneca Pharmaceuticals. Revised July 2015.

30. IRESSA (gefitinib) tablets: Summary of product characteristics. AstraZeneca. Available from: https://www.ema.europa.eu/en/docu ments/product-information/iressa-epar-product-information_en.pdf. Accessed June 14, 2019. 
31. Betta Pharmaceuticals Co., Ltd. Icotinib [webpage on the Internet]. Hangzhou: Betta Pharmaceuticals Co., Ltd. Available from: http://en. bettapharma.com/Product.aspx. Accessed August 3, 2018.

32. Maemondo $\mathrm{M}$, Inoue $\mathrm{A}$, Kobayashi $\mathrm{K}$, et al. Gefitinib or chemotherapy for non-small-cell lung cancer with mutated EGFR. $N$ Engl J Med. 2010;362(25):2380-2388. doi:10.1056/ NEJMoa0909530

33. Mitsudomi T, Morita S, Yatabe Y, et al. Gefitinib versus cisplatin plus docetaxel in patients with non-small-cell lung cancer harbouring mutations of the epidermal growth factor receptor (WJTOG3405): an open label, randomised phase 3 trial. Lancet Oncol. 2010;11(2):121-128. doi:10.1016/S14702045(09)70364-X

34. Rosell R, Carcereny E, Gervais R, et al. Erlotinib versus standard chemotherapy as first-line treatment for European patients with advanced EGFR mutation-positive non-small-cell lung cancer (EURTAC): a multicentre, open-label, randomised phase 3 trial. Lancet Oncol. 2012;13(3):239-246. doi:10.1016/S1470-2045(11) 70393-X

35. Shi YK, Wang L, Han BH, et al. First-line icotinib versus cisplatin/ pemetrexed plus pemetrexed maintenance therapy for patients with advanced EGFR mutation-positive lung adenocarcinoma (CONVINCE): a phase 3, open-label, randomized study. Ann Oncol. 2017;28(10):2443-2450. doi:10.1093/annonc/mdx359

36. Wu YL, Zhou C, Liam CK, et al. First-line erlotinib versus gemcitabine/cisplatin in patients with advanced EGFR mutation-positive non-small-cell lung cancer: analyses from the phase III, randomized, open-label, ENSURE study. Ann Oncol. 2015;26 (9):1883-1889. doi:10.1093/annonc/mdv270

37. Zhou C, Wu YL, Chen G, et al. Erlotinib versus chemotherapy as first-line treatment for patients with advanced EGFR mutation-positive non-small-cell lung cancer (OPTIMAL, CTONG-0802): a multicentre, open-label, randomised, phase 3 study. Lancet Oncol. 2011;12(8):735-742. doi:10.1016/S14702045(11)70184-X

38. Arcila ME, Oxnard GR, Nafa K, et al. Rebiopsy of lung cancer patients with acquired resistance to EGFR inhibitors and enhanced detection of the T790M mutation using a locked nucleic acid-based assay. Clin Cancer Res. 2011;17(5):1169-1180. doi:10.1158/10780432.CCR-10-2277

39. Pao W, Miller VA, Politi KA, et al. Acquired resistance of lung adenocarcinomas to gefitinib or erlotinib is associated with a second mutation in the EGFR kinase domain. PLoS Med. 2005;2(3):e73. doi:10.1371/journal.pmed.0020073

40. Sequist LV, Waltman BA, Dias-Santagata D, et al. Genotypic and histological evolution of lung cancers acquiring resistance to EGFR inhibitors. Sci Transl Med. 2011;3(75):75ra26. doi:10.1126/ scitranslmed.3002003

41. Bean J, Brennan C, Shih JY, et al. MET amplification occurs with or without T790M mutations in EGFR mutant lung tumors with acquired resistance to gefitinib or erlotinib. Proc Natl Acad Sci $U S$ A. 2007;104(52):20932-20937. doi:10.1073/pnas.071037 0104

42. Engelman JA, Zejnullahu K, Mitsudomi T, et al. MET amplification leads to gefitinib resistance in lung cancer by activating ERBB3 signaling. Science. 2007;316(5827):1039-1043. doi:10.1126/ science. 1141478

43. Cappuzzo F, Ligorio C, Janne PA, et al. Prospective study of gefitinib in epidermal growth factor receptor fluorescence in situ hybridization-positive/phospho-Akt-positive or never smoker patients with advanced non-small-cell lung cancer: the ONCOBELL trial. J Clin Oncol. 2007;25(16):2248-2255. doi:10.1200/JCO.2006.09.4300

44. Sasaki H, Endo K, Takada M, et al. EGFR exon 20 insertion mutation in Japanese lung cancer. Lung Cancer. 2007;58 (3):324-328. doi:10.1016/j.lungcan.2007.06.024
45. Engelman JA, Zejnullahu K, Gale CM, et al. PF00299804, an irreversible pan-ERBB inhibitor, is effective in lung cancer models with EGFR and ERBB2 mutations that are resistant to gefitinib. Cancer Res. 2007;67(24):11924-11932. doi:10.1158/0008-5472. CAN-07-1885

46. Li D, Ambrogio L, Shimamura T, et al. BIBW2992, an irreversible EGFR/HER2 inhibitor highly effective in preclinical lung cancer models. Oncogene. 2008;27(34):4702-4711. doi:10.1038/ onc.2008.109

47. Ninomiya $\mathrm{T}$, Takigawa N, Ichihara E, et al. Afatinib prolongs survival compared with gefitinib in an epidermal growth factor receptor-driven lung cancer model. Mol Cancer Ther. 2013;12 (5):589-597. doi:10.1158/1535-7163.MCT-12-0885

48. Perera SA, Li D, Shimamura T, et al. HER2YVMA drives rapid development of adenosquamous lung tumors in mice that are sensitive to BIBW2992 and rapamycin combination therapy. Proc Natl Acad Sci U S A. 2009;106(2):474 479. doi:10.1073/pnas.0808930106

49. Gonzales AJ, Hook KE, Althaus IW, et al. Antitumor activity and pharmacokinetic properties of PF-00299804, a second-generation irreversible pan-erbB receptor tyrosine kinase inhibitor. Mol Cancer Ther. 2008;7(7):1880-1889. doi:10.1158/1535-7163.MCT-07-2232

50. Yang JC, Wu YL, Schuler M, et al. Afatinib versus cisplatin-based chemotherapy for EGFR mutation-positive lung adenocarcinoma (LUX-Lung 3 and LUX-Lung 6): analysis of overall survival data from two randomised, phase 3 trials. Lancet Oncol. 2015;16 (2):141-151. doi:10.1016/S1470-2045(14)71173-8

51. Park K, Tan EH, O'Byrne K, et al. Afatinib versus gefitinib as first-line treatment of patients with EGFR mutation-positive non-small-cell lung cancer (LUX-Lung 7): a phase 2B, open-label, randomised controlled trial. Lancet Oncol. 2016;17 (5):577-589. doi:10.1016/S1470-2045(16)30033-X

52. Paz-Ares L, Tan EH, O'Byrne K, et al. Afatinib versus gefitinib in patients with EGFR mutation-positive advanced non-small-cell lung cancer: overall survival data from the phase IIb LUX-Lung 7 trial. Ann Oncol. 2017;28(2):270-277. doi:10.1093/annonc/mdw611

53. Kato T, Yoshioka H, Okamoto I, et al. Afatinib versus cisplatin plus pemetrexed in Japanese patients with advanced non-small cell lung cancer harboring activating EGFR mutations: subgroup analysis of LUX-Lung 3. Cancer Sci. 2015;106(9):1202-1211. doi:10.1111/ cas. 12723

54. Wu Y-L, Xu C-R, Hu C-P, et al. Afatinib versus gemcitabine/ cisplatin for first-line treatment of Chinese patients with advanced non-small-cell lung cancer harboring EGFR mutations: subgroup analysis of the LUX-Lung 6 trial. Onco Targets Ther. 2018;11:8575-8587. doi:10.2147/OTT.S160358

55. GILOTRIF ${ }^{\circledR}$ (afatinib) tablets, for oral use[prescribing information]. Ridgefield, CT: Boehringer Ingelheim Pharmaceuticals, Inc. Revised January 2018.

56. GIOTRIF (afatinib) tablets: Summary of Product Characteristics. Boehringer Ingelheim International GmbH. Available from: https:// www.ema.europa.eu/en/documents/product-information/giotrifepar-product-information_en.pdf. Accessed June 14, 2019.

57. Janne PA, Ou SH, Kim DW, et al. Dacomitinib as first-line treatment in patients with clinically or molecularly selected advanced non-small-cell lung cancer: a multicentre, open-label, phase 2 trial. Lancet Oncol. 2014;15(13):1433-1441. doi:10.1016/S1470-2045(14)70461-9

58. Wu YL, Cheng Y, Zhou X, et al. Dacomitinib versus gefitinib as first-line treatment for patients with EGFR-mutation-positive non-small-cell lung cancer (ARCHER 1050): a randomised, open-label, phase 3 trial. Lancet Oncol. 2017;18(11):1454-1466. doi:10.1016/S1470-2045(17)30608-3

59. Mok TS, Cheng Y, Zhou X, et al. Improvement in overall survival in a randomized study that compared dacomitinib with gefitinib in patients with advanced non-small-cell lung cancer and EGFR-activating mutations. J Clin Oncol. 2018;36 (22):2244-2250. doi:10.1200/JCO.2018.78.7994 
60. Zhang Y, Zhang Z, Huang X, et al. Therapeutic efficacy comparison of 5 major EGFR-TKIs in advanced EGFR-positive non-small-cell lung cancer: a network meta-analysis based on head-to-head trials. Clin Lung Cancer. 2017;18(5):e333-e340. doi:10.1016/j.cllc.2016.09.006

61. Kuan F-C, Kuo L-T, Yang W-H, et al. Dissecting the prognostic role of common EGFR-mutations of metastatic NSCLC in TKI era: A systematic review and subgroup meta-analysis. J Clin Oncol. 2018;36(15_suppl):9079. doi:10.1200/JCO.2018.36.15_suppl.9079

62. Fujiwara A, Yoshida $\mathrm{M}$, Fujimoto $\mathrm{H}$, et al. A retrospective comparison of the clinical efficacy of gefitinib, erlotinib and afatinib in Japanese patients with non-small cell lung cancer. Oncol Res. 2018;26:1031-1036. doi:10.3727/096504018X15151 523767752

63. Kim Y, Lee SH, Ahn JS, Ahn M-J, Park K, Sun J-M. Efficacy and safety of afatinib for EGFR-mutant non-small cell lung cancer, compared with gefitinib or erlotinib. Cancer Res Treat. 2019;51 (2):502-509. doi:10.4143/crt.2018.117

64. Kuan FC, Li SH, Wang CL, Lin M-H, Tsai Y-H, Yang C-T. Analysis of progression-free survival of first-line tyrosine kinase inhibitors in patients with non-small cell lung cancer harboring leu858Arg or exon 19 deletions. Oncotarget. 2017;8 (1):1343-1353. doi:10.18632/oncotarget.13815

65. Tu CY, Chen CM, Liao WC, et al. Comparison of the effects of the three major tyrosine kinase inhibitors as first-line therapy for non-small-cell lung cancer harboring epidermal growth factor receptor mutations. Oncotarget. 2018;9(36):24237-24247. doi:10.18632/oncotarget.24386

66. Liang SK, Hsieh MS, Lee MR, et al. Real-world experience of afatinib as a first-line therapy for advanced EGFR mutation-positive lung adenocarcinoma. Oncotarget. 2017;8 (52):90430-90443. doi:10.18632/oncotarget.19563

67. Tan WL, Toh CK, Lim C, et al. First-line afatinib experience in EGFR-mutant $(\mathrm{M}+)$ lung cancer [poster presentation]. Abstract B0129. Poster presented at: 20th Annual Meeting of Chinese Society of Clinical Oncology; 2017; Xiamen, China.

68. Tokaca N, O'Brien M, Bhosle J, et al. 149P Real-world outcomes with first-line afatinib in EGFR mutant NSCLC adenocarcinoma: A single centre experience exploring effects of dose-reduction. $J$ Thorac Oncol. 2018;13(4):S89-S90. doi:10.1016/S15560864(18)30423-4

69. Wu YL, Tu H, Feng J, et al. P3.01-036 A Phase IIIb open-label, single-arm study of afatinib in EGFR TKI-naïve patients with EGFRm+ NSCLC: an interim analysis [poster presentation] IASLC 18th World Congress on Lung Cancer. Yokohama, Japan: 2017:Abstract 03.01-015.

70. Lau SC, Chooback N, Ho CC, et al. P3.01-015 Differential outcomes between first and second generation TKIs in patients with activating EGFR mutations in NSCLC [poster presentation]. IASLC 18th World Congress on Lung Cancer. Yokohama, Japan: 2017: Abstract 03.01-015.

71. Chiu CH, Yang CT, Shih JY, et al. Epidermal growth factor receptor tyrosine kinase inhibitor treatment response in advanced lung adenocarcinomas with G719X/L861Q/S768I mutations. $J$ Thorac Oncol. 2015;10(5):793-799. doi:10.1097/JTO. 0000000000000504

72. Wu JY, Yu CJ, Chang YC, Yang C-H, Shih J-Y, Yang P-C. Effectiveness of tyrosine kinase inhibitors on "uncommon" epidermal growth factor receptor mutations of unknown clinical significance in non-small cell lung cancer. Clin Cancer Res. 2011;17 (11):3812-3821. doi:10.1158/1078-0432.CCR-10-3408

73. Yang CH, Yu CJ, Shih JY, et al. Specific EGFR mutations predict treatment outcome of stage IIIB/IV patients with chemotherapy-naive non-small-cell lung cancer receiving first-line gefitinib monotherapy. J Clin Oncol. 2008;26(16):2745-2753. doi:10.1200/JCO.2007.15.6695
74. Watanabe S, Minegishi Y, Yoshizawa H, et al. Effectiveness of gefitinib against non-small-cell lung cancer with the uncommon EGFR mutations G719X and L861Q. J Thorac Oncol. 2014;9 (2):189-194. doi:10.1097/JTO.0000000000000048

75. Baek JH, Sun JM, Min YJ, et al. Efficacy of EGFR tyrosine kinase inhibitors in patients with EGFR-mutated non-small cell lung cancer except both exon 19 deletion and exon 21 L858R: a retrospective analysis in Korea. Lung Cancer. 2015;87 (2):148-154. doi:10.1016/j.lungcan.2014.11.013

76. Klughammer B, Brugger W, Cappuzzo F, et al. Examining treatment outcomes with erlotinib in patients with advanced non-small cell lung cancer whose tumors harbor uncommon EGFR mutations. $J$ Thorac Oncol. 2016;11(4):545-555. doi:10.1016/j.jtho.2015.12.107

77. Xu J, Jin B, Chu T, et al. EGFR tyrosine kinase inhibitor (TKI) in patients with advanced non-small cell lung cancer (NSCLC) harboring uncommon EGFR mutations: a real-world study in China. Lung Cancer. 2016;96:87-92. doi:10.1016/j.lungcan.2016.01.018

78. Banno E, Togashi Y, Nakamura Y, et al. Sensitivities to various epidermal growth factor receptor-tyrosine kinase inhibitors of uncommon epidermal growth factor receptor mutations L861Q and S768I: what is the optimal epidermal growth factor receptor-tyrosine kinase inhibitor? Cancer Sci. 2016;107(8):1134-1140. doi:10.1111/cas.12980

79. Kobayashi Y, Togashi Y, Yatabe Y, et al. EGFR exon 18 mutations in lung cancer: molecular predictors of augmented sensitivity to afatinib or neratinib as compared with first- or third-generation TKIs. Clin Cancer Res. 2015;21(23):5305-5313. doi:10.1158/ 1078-0432.CCR-15-1046

80. Saxon JA, Sholl LM, Janne PA. EGFR L858M/L861Q cis mutations confer selective sensitivity to afatinib. J Thorac Oncol. 2017;12(5):884-889. doi:10.1016/j.jtho.2017.01.006

81. Yang JC, Shih JY, Su WC, et al. Afatinib for patients with lung adenocarcinoma and epidermal growth factor receptor mutations (LUX-Lung 2): a phase 2 trial. Lancet Oncol. 2012;13(5):539-548. doi:10.1016/S1470-2045(12)70086-4

82. Wu YL, Sequist LV, Tan EH, et al. Afatinib as first-line treatment of older patients with EGFR mutation-positive non-small-cell lung cancer: subgroup analyses of the LUX-Lung 3, LUX-Lung 6, and LUX-Lung 7 trials. Clin Lung Cancer. 2018;19(4):e465-e479. doi:10.1016/j.cllc.2018.03.009

83. Hochmair MJ, Morabito A, Hao D, et al. Sequential treatment with afatinib and osimertinib in patients with EGFR mutation-positive non-small-cell lung cancer: an observational study. Future Oncol. 2018;14(27):2861-2874. doi:10.2217/fon-2018-0711

84. Rangachari D, Yamaguchi N, VanderLaan PA, et al. Brain metastases in patients with EGFR-mutated or ALK-rearranged non-small-cell lung cancers. Lung Cancer. 2015;88(1):108-111. doi:10.1016/j.lungcan.2015.01.020

85. Iuchi T, Shingyoji M, Itakura M, et al. Frequency of brain metastases in non-small-cell lung cancer, and their association with epidermal growth factor receptor mutations. Int $\mathrm{J}$ Clin Oncol. 2015;20(4):674-679. doi:10.1007/s10147-014-0760-9

86. Zhang SR, Zhu LC, Jiang YP, et al. Efficacy of afatinib, an irreversible ErbB family blocker, in the treatment of intracerebral metastases of non-small cell lung cancer in mice. Acta Pharmacol Sin. 2017;38(2):233-240. doi:10.1038/aps.2016.107

87. Hoffknecht P, Tufman A, Wehler T, et al. Efficacy of the irreversible ErbB family blocker afatinib in epidermal growth factor receptor (EGFR) tyrosine kinase inhibitor (TKI)-pretreated non-small-cell lung cancer patients with brain metastases or leptomeningeal disease. $J$ Thorac Oncol. 2015;10(1):156-163. doi:10.1097/JTO.0000000000000380

88. Tamiya A, Tamiya M, Nishihara T, et al. Cerebrospinal fluid penetration rate and efficacy of afatinib in patients with EGFR mutation-positive non-small cell lung cancer with leptomeningeal carcinomatosis: a multicenter prospective study. Anticancer Res. 2017;37(8):4177-4182. doi:10.21873/anticanres.11806 
89. Togashi Y, Masago K, Masuda S, et al. Cerebrospinal fluid concentration of gefitinib and erlotinib in patients with non-small cell lung cancer. Cancer Chemother Pharmacol. 2012;70(3):399-405. doi:10.1007/s00280-012-1929-4

90. Schuler M, Wu YL, Hirsh V, et al. First-line afatinib versus chemotherapy in patients with non-small cell lung cancer and common epidermal growth factor receptor gene mutations and brain metastases. $J$ Thorac Oncol. 2016;11(3):380-390. doi:10.1016/j.jtho.2015.11.014

91. Girard N. Optimizing outcomes in EGFR mutation-positive NSCLC: which tyrosine kinase inhibitor and when? Future Oncol. 2018;14(11):1117-1132. doi:10.2217/fon-2017-0636

92. Li SH, Liu CY, Hsu PC, et al. Response to afatinib in treatment-naive patients with advanced mutant epidermal growth factor receptor lung adenocarcinoma with brain metastases. Expert Rev Anticancer Ther. 2018;18(1):81-89. doi:10.1080/14737140.2018.1409623

93. Kim Y, Sun J-M, Lee S-H, et al. P3.01-023 First-line afatinib for non-small-cell lung cancer in real-world practice [poster presentation]. IASLC 18th World Congress on Lung Cancer. Yokohama, Japan: 2017:Abstract P3.01-023.

94. Tanaka K, Nosaki K, Otsubo K, et al. Acquisition of the T790M resistance mutation during afatinib treatment in EGFR tyrosine kinase inhibitor-naive patients with non-small cell lung cancer harboring EGFR mutations. Oncotarget. 2017;8(40):68123-68130. doi:10.18632/oncotarget.19243

95. Wu SG, Liu YN, Tsai MF, et al. The mechanism of acquired resistance to irreversible EGFR tyrosine kinase inhibitor-afatinib in lung adenocarcinoma patients. Oncotarget. 2016;7 (11):12404-12413. doi:10.18632/oncotarget.7189

96. Yang JC, Ahn MJ, Kim DW, et al. Osimertinib in pretreated T790M-positive advanced non-small-cell lung cancer: AURA study phase II extension component. J Clin Oncol. 2017;35 (12):1288-1296. doi:10.1200/JCO.2016.70.3223

97. Hochmair MJ, Buder A, Schwab S, et al. Liquid-biopsy-based identification of EGFR T790M mutation-mediated resistance to afatinib treatment in patients with advanced EGFR mutation-positive NSCLC, and subsequent response to osimertinib. Target Oncol. 2019;14(1):75-83. doi:10.1007/s11523-018-0612-z

98. Kobayashi Y, Azuma K, Nagai H, et al. Characterization of EGFR T790M, L792F, and C797S mutations as mechanisms of acquired resistance to afatinib in lung cancer. Mol Cancer Ther. 2017;16 (2):357-364. doi:10.1158/1535-7163.MCT-16-0407

99. TAGRISSO ${ }^{\mathrm{TM}}$ (osimertinib) tablet, for oral use [prescribing information]. Wilmington, DE: AstraZeneca Pharmaceuticals; Revised April 2018.

100. Soria JC, Ohe Y, Vansteenkiste J, et al. Osimertinib in untreated EGFR-mutated advanced non-small-cell lung cancer. $N \mathrm{Engl}$ J Med. 2018;378(2):113-125. doi:10.1056/NEJMoa1713137

101. Lin JZ, Ma SK, Wu SX, Yu S-H, Li X-Y. A network meta-analysis of nonsmall-cell lung cancer patients with an activating EGFR mutation: should osimertinib be the first-line treatment? Medicine (Baltimore). 2018;97(30):e11569. doi:10.1097/MD.0000000000011569
102. Ramalingam SS, Cheng Y, Zhou C, et al. Mechanisms of acquired resistance to first-line osimertinib: preliminary data from the phase III FLAURA study [poster presentation]. ESMO 2018 Congress. Munich, Germany: 2018: AbstractLBA50.

103. Mok TS, Wu YL, Ahn MJ, et al. Osimertinib or platinum-pemetrexed in EGFR T790M-positive lung cancer. $N$ Engl J Med. 2017;376 (7):629-640. doi:10.1056/NEJMoa1612674

104. Sequist LV, Wu YL, Schuler M, et al. Subsequent therapies post-afatinib among patients with EGFR mutation-positive NSCLC in LUX-Lung (LL) 3, 6 and 7 [poster presentation]. Abstract 1349P. Poster presented at: ESMO 2017 Congress; Madrid, Spain.

105. Hirsh V. Turning EGFR mutation-positive non-small-cell lung cancer into a chronic disease: optimal sequential therapy with EGFR tyrosine kinase inhibitors. Ther Adv Med Oncol. 2018;10:1758834017753338. doi:10.1177/1758834017753338

106. Piotrowska Z, Gainor JF. ARCHER 1050: hitting an important mark in EGFR-mutant lung cancer? J Clin Oncol. 2018;36:2241-2243. doi:10.1200/JCO.2018.79.3059

107. Bennouna J. Update on afatinib-based combination regimens for the treatment of EGFR mutation-positive non-small-cell lung cancer. Future Oncol. 2017;13(21):1829-1833. doi:10.2217/fon-2017-0240

108. Janjigian YY, Smit EF, Groen HJ, et al. Dual inhibition of EGFR with afatinib and cetuximab in kinase inhibitor-resistant EGFR-mutant lung cancer with and without T790M mutations. Cancer Discov. 2014;4 (9):1036-1045. doi:10.1158/2159-8290.CD-14-0326

109. Schuler M, Yang JC, Park K, et al. Afatinib beyond progression in patients with non-small-cell lung cancer following chemotherapy, erlotinib/gefitinib and afatinib: phase III randomized LUX-Lung 5 trial. Ann Oncol. 2016;27(3):417-423. doi:10.1093/annonc/mdv597

110. Hata A, Katakami N, Kaji R, et al. Afatinib plus bevacizumab combination after acquired resistance to EGFR tyrosine kinase inhibitors in EGFR-mutant non-small cell lung cancer: multicenter, single-arm, phase 2 trial (ABC Study). Cancer. 2018;124 (19):3830-3838. doi:10.1002/cncr.31678

111. Ding PN, Lord SJ, Gebski V, et al. Risk of treatment-related toxicities from EGFR tyrosine kinase inhibitors: a meta-analysis of clinical trials of gefitinib, erlotinib, and afatinib in advanced EGFR-mutated non-small cell lung cancer. $J$ Thorac Oncol. 2017;12(4):633-643. doi:10.1016/j.jtho.2016.11.2236

112. Yang JC, Sequist LV, Zhou C, et al. Effect of dose adjustment on the safety and efficacy of afatinib for EGFR mutation-positive lung adenocarcinoma: post hoc analyses of the randomized LUX-Lung 3 and 6 trials. Ann Oncol. 2016;27(11):2103-2110. doi:10.1093/ annonc/mdw322

113. Liang SK, Lee MR, Liao WY, et al. Prognostic factors of afatinib as a first-line therapy for advanced EGFR mutation-positive lung adenocarcinoma: a real-world, large cohort study. Oncotarget. 2018;9(34):23749-23760. doi:10.18632/oncotarget.25255
OncoTargets and Therapy

\section{Publish your work in this journal}

OncoTargets and Therapy is an international, peer-reviewed, open access journal focusing on the pathological basis of all cancers, potential targets for therapy and treatment protocols employed to improve the management of cancer patients. The journal also focuses on the impact of management programs and new therapeutic agents and protocols on patient perspectives such as quality of life, adherence and satisfaction. The manuscript management system is completely online and includes a very quick and fair peer-review system, which is all easy to use. Visit http://www.dovepress.com/ testimonials.php to read real quotes from published authors. 